\title{
The associations of poor psychiatric well-being among incarcerated men with injecting drug use histories in Victoria, Australia
}

Reece Cossar ${ }^{1,2^{*}}$ (D) Mark Stoové 2,3 $^{2}$, Stuart A. Kinner $3,4,5,6,7$, Paul Dietze ${ }^{2,3}$, Campbell Aitken ${ }^{2,3}$, Michael Curtis ${ }^{2}$, Amy Kirwan ${ }^{2}$ and James R. P. Ogloff ${ }^{1}$

\begin{abstract}
Background: Dual substance dependence and psychiatric and psychological morbidities are overrepresented in prison populations and associated with reoffending. In the context of an increasing prison population in Australia, investigating the needs of vulnerable people in prison with a dual diagnosis can help inform in-prison screening and treatment and improve prison and community service integration and continuation of care. In this study we quantified psychiatric well-being in a sample of people in prison with a history of injecting drug use in Victoria, Australia, and identified factors associated with this outcome.

Methods and Results: Data for this paper come from baseline interviews undertaken in the weeks prior to release as part of a prospective cohort study of incarcerated men who reported regular injecting drug use prior to their current sentence. Eligible participants completed a researcher-administered structured questionnaire that canvassed a range of issues. Psychiatric well-being was assessed using the 12-item General Health Questionnaire (GHQ-12) and potential correlates were included based on a review of the literature. Of the 317 men included for analyses, 139 were classified as experiencing current poor psychiatric well-being. In the multivariate model using modified logistic regression, history of suicide attempt $(\mathrm{aOR}=1.36,95 \% \mathrm{Cl} 1.03-1.78)$, two or more medical conditions ( $\mathrm{aOR}=1.87,95 \% \mathrm{Cl} 1.30-2.67$ ) and use of crystal methamphetamine in the week prior to their current sentence $(\mathrm{aOR}=1.52,95 \% \mathrm{Cl} 1.05-2.22)$ were statistically significantly associated with current poor psychiatric well-being.

Conclusions: Comprehensively addressing the health-related needs for this vulnerable population will require a multidisciplinary approach and enhancing opportunities to screen and triage people in prison for mental health and other potential co-occurring health issues will provide opportunities to better address individual health needs and reoffending risk.
\end{abstract}

Keywords: Injecting drug use, Dual diagnosis, GHQ-12, Prisoner health

\footnotetext{
* Correspondence: reece.cossar@burnet.edu.au

${ }^{1}$ Centre for Forensic Behavioural Science, Swinburne University of

Technology \& Forensicare, Melbourne, Australia

${ }^{2}$ Behaviours and Health Risks, Burnet Institute, Melbourne, Australia

Full list of author information is available at the end of the article
} 


\section{Background}

Over the past decade, the Victorian incarceration rate has increased from 100 per 100,000 adults in 2006 to 138 per 100,000 adults in 2016 (Australian Bureau of Statistics, 2016). People with a history of injecting drug use are over-represented in the Australian prison population. An estimated half of Australian prisons report a lifetime history of injecting drug use and approximately one in four reports at least one injection episode in the month prior to incarceration (Australian Institute of Health and Welfare, 2015; Reekie et al., 2014). People who inject drugs (PWID) face a heightened risk of bloodborne viral infections (Snow et al., 2014; Vescio et al., 2008), suicide (Artenie et al., 2015), overdose following release (Winter et al., 2015), and reduced personal well-being (Scott et al., 2017).

People experience disproportionate levels of psychiatric and psychological problems in prison relative to people in the community (Fazel \& Baillargeon, 2010; Markowitz, 2011; Sirdifield et al., 2009). Australian research findings suggest that $44 \%$ of prison entrants have a mental health condition (Australian Institute of Health and Welfare, 2015; Schilders \& Ogloff, 2016). Many present with multiple diagnoses (Sirdifield et al., 2009), including schizophrenia (Chang et al., 2015; Davis et al., 2007; Munetz et al., 2001), major mood disorders (Brink et al., 2001), anxiety disorders (Butler et al., 2011), posttraumatic stress disorder (Ogloff et al., 2017), anti-social personality disorder (Fazel \& Danesh, 2002), traumatic brain injury (Durand et al., 2017; O’Rourke et al., 2016), and cognitive impairment (Dias et al., 2013; McCausland et al., 2013). Limited access to prison mental healthcare services in some correctional settings mean the needs of many people detained in prison with psychiatric or psychological problems may not be adequately met (Senior et al., 2013). Upon reception into a Victorian correctional setting all prison entrants undertake a mental health screen, typically conducted by correctional staff (Every-Palmer et al., 2014) who may be inadequately trained. In addition, specialist mental health staff may provide voluntary assessment and treatment for people detained in prison throughout Victorian correctional settings. People detained in prison requiring court ordered or involuntary assessment and treatment are transferred to the Victorian secure forensic hospital under the Mental Health Act 2014 (Vic).

Dual diagnosis - a term used to describe the cooccurrence of substance dependence with one or more psychiatric disorders - compounds the independent impact of drug dependence and mental health problems and is widely documented in prison studies (Drake \& Wallach, 2000; Ogloff et al., 2004; Ogloff et al., 2015). The health profile of people in prison with dual diagnosis demands a multidisciplinary medical, psychological, and social needs approach to address extensive criminal histories (Kinner, 2006; Ogloff et al., 2015), poor quality of life (Warden et al., 2016), reduced treatment engagement (Horsfall et al., 2009), and high reoffending risk (Ogloff et al., 2004; Youssef et al., 2016). Although there are numerous studies of people in prison with injecting drug histories, comparatively few investigate co-occurring psychiatric well-being and substance use in detail. In the context of a rapidly increasing global prison population, characterising people in prison with histories of injecting drug usewith current poor psychiatric well-being could help identify unmet needs for targeted screening, improved integration of prison and community service models of care, and post-release continuation of care.

In this study we identify associations of psychiatric well-being in a cohort of incarcerated men with histories of injecting drug use, four to 6 weeks prior to release from prison. Whereas previous studies have typically examined substance use problems in people in prison with a mental health condition, our focus is on the mental health of people who inject drugs. People in prison require varying degrees of support to facilitate a successful release, and inadequate pre-release planning has been shown to be a barrier to successful reintegration from prison to community (Butzin et al., 2005). Identifying high-risk, vulnerable subpopulations oof people detained in prison prior to release could inform evidence-based policy to target transitional support services for those most at-risk of reoffending and substance use relapse.

\section{Method}

\section{Study design, sample and setting}

Data for this paper come from baseline interviews $(N=400)$ from the Prison and Transition Health study, which is a prospective cohort study of incarcerated men who reported regular injecting drug use prior to their current sentence. Interviews with eligible participants occur at three, 12, and 24 month time points post release from prison. Participants were recruited from one maximum, one medium, and one minimum-security correctional facility in the Australian state of Victoria to ensure a representative sample of people with regular histories of injecting drug use. Interviews occurred between the September 17, 2014 and May 24, 2016. Eligible participants ( $\geq 18$ years of age, injecting at least monthly in the 6 months prior to their current sentence, expected release in the succeeding 4 weeks, and able to provide informed, written consent) completed a researcher-administered structured questionnaire that canvassed a range of issues (detailed below), typically taking 45-60 min. People on remand (pre-trial detention) were excluded from the study.

The study was approved by the Alfred Hospital Human Research Ethics Committee (79/12) and the Victorian 
Department of Justice Human Research Ethics Committee (CF/14/10169).

\section{Measures \\ Outcome measure}

Psychiatric well-being was assessed using the 12itemGeneral Health Questionnaire (GHQ-12), a wellvalidated screening instrument for identifying current poor psychiatric well-being. Participants rate themselves according to the degree to which they have experienced each of 12 symptoms over the past few weeks, using a four-point Likert scale. The standard method of scoring is that symptomatic responses are scored ' 1 ' and non-symptomatic responses are scored '0' (Goldberg, 1992; Goldberg et al., 1997), resulting in overall scores ranging from zero to 12 . Mean derived cut-off thresholds are considered the most appropriate method of identifying current poor psychiatric well-being (Goldberg et al., 1998).

\section{Considered correlates}

Based on a review of literature, a range of potential correlates of psychiatric well-being was selected from the sociodemographic, health, criminological, alcohol and other drug use, and adverse childhood experiences domains.

Sociodemographic Age $(\leq 30 / 31-40 / \geq 41)$, number of years of education completed $(\leq 9 / \geq 10$ years completed), accommodation status (stable (owner occupied, private rental, or public housing)/unstable (parent/sibling/other family's home, boarding house, crisis accommodation, staying with friend, squat, homeless), and Aboriginal and/ or Torres Strait Islander identification (no/yes).

Health Attempted suicide ever (no/yes), number of selfreported medical (respiratory, circulatory, musculoskeletal, neurological, hearing, vision or metabolic) conditions (none/one/ $\geq$ two), self-reported hepatitis $\mathrm{C}$ status (negative or don't know/positive), and self-reported acquired brain injury (no/yes).

Criminological Prison security level (maximum/medium/ minimum), youth detention ever (no/yes), number of previous adult incarcerations $(0-3 / \geq 4)$, and Level of Service Inventory - Revised: Screening Version (Andrews \& Bonta, 1998 - continuous); an eight-item quantitative screening tool used to determine level of service and supervision required to help focus treatment plans and predict future reoffending risk (Ferguson et al., 2009). A score of three or more suggests further follow-up with the individual is required.

Alcohol and other drug use Age first injected ( $\leq 16 / 17-$ $20 / \geq 21$ ), poly-drug injecting drug use in the month before their current sentence (no/yes), illicit substances used by any route of administration (heroin only/crystal methamphetamines only/heroin and crystal methamphetamines) in the week before their current sentence, and high risk alcohol consumption (at least two times per week and at least five or more drinks per usual drinking episode) in the year before their current sentence (no/yes).

Adverse childhood experiences Removed from family home as a child ever (no/yes) and expelled from school ever (no/yes).

\section{Statistical analysis}

Descriptive statistics were generated for each variable with respect to psychiatric well-being according to the GHQ-12. Potential correlates were examined using modified Poisson regression with robust standard errors, using odds ratios (OR/adjusted OR (aOR)) and 95\% confidence intervals $(95 \% \mathrm{CI})$. Bivariate analyses were conducted to examine associations between each potential correlate and psychiatric well-being. A multivariable model was constructed in which all potential correlates were included to determine the individual effects of each potential correlate after adjustment for others, with a complete case approach used. Statistical significance set at $p<0.05$. All analyses were conducted with Stata 14 for Windows (StataCorp, 2015).

\section{Results}

\section{Sample characteristics}

Characteristics of the sample according to level of psychiatric well-being are shown in Table 1. Eighty-three participants were excluded due to incomplete data. In our sample a total GHQ-12 score of three or more $\left(M_{\mathrm{GHQ}-12}=3.13, S D=3.24\right)$ was indicative of current poor psychiatric well-being. Of the 317 men $\left(M_{\text {age }}=36.1\right.$, $S D=8.47)$ included for full case analysis, 139 (44\%) were classified as experiencing current poor psychiatric wellbeing. The sample were mostly born in Australia (89\%), lived in a metropolitan area before their current sentence (56\%), identified as heterosexual (98\%), and expected straight (under no supervision) release (70\%). Methamphetamine (53\%) was the drug type first injected by most, followed by heroin $(37 \%)$. Nine $(3 \%)$ of the men were homeless or had no fixed address prior to their current sentence. There was a high prevalence of self-reported depression (64\%), anxiety (52\%), schizophrenia (15\%), anti-social personality disorder (9\%), and bi-polar disorder (16\%). Two thirds of the sample (64\%) selfreportedhepatitis $\mathrm{C}$ infection and only one participant reported no prior adult incarceration. 
Table 1 Participant characteristics and modified poisson regression associations with poor psychiatric well-being among incarcerated men who reported regular injecting drug use prior to their current sentence $(n=317)$

\begin{tabular}{|c|c|c|c|c|}
\hline & $\begin{array}{l}\text { GHQ-12 } \\
(\geq 3) \\
(n=139)\end{array}$ & $\begin{array}{l}\text { GHQ-12 } \\
(\leq 2) \\
(n=178)\end{array}$ & $\mathrm{OR}^{\mathrm{a}}(95 \% \mathrm{Cl})$ & $\mathrm{aOR} \mathrm{R}^{\mathrm{b}}(95 \% \mathrm{Cl})$ \\
\hline \multicolumn{5}{|l|}{ Socio-demographic } \\
\hline \multicolumn{5}{|l|}{ Age } \\
\hline$\leq 30$ & $38(27)$ & $48(28)$ & 1 & 1 \\
\hline $31-40$ & $65(47)$ & $66(38)$ & $1.15(0.88-1.51)$ & $1.33(0.97-1.82)$ \\
\hline$\geq 41$ & $36(26)$ & $59(34)$ & $0.88(0.64-1.21)$ & $1.08(0.73-1.60)$ \\
\hline \multicolumn{5}{|l|}{ Number of years of education completed } \\
\hline$\leq 9$ years completed & $58(42)$ & $78(44)$ & 1 & 1 \\
\hline$\geq 10$ years completed & $81(58)$ & $100(56)$ & $1.23(0.95-1.59)$ & $1.18(0.90-1.56)$ \\
\hline \multicolumn{5}{|l|}{ Accommodation status } \\
\hline Stable & $72(52)$ & $94(53)$ & 1 & 1 \\
\hline Unstable & $67(48)$ & $84(47)$ & $0.96(0.76-1.21)$ & $0.98(0.77-1.26)$ \\
\hline \multicolumn{5}{|c|}{ Aboriginal and/or Torres Strait Islander identification } \\
\hline No & $109(78)$ & $151(85)$ & 1 & 1 \\
\hline Yes & $30(22)$ & $27(15)$ & $0.82(0.63-1.07)$ & $0.90(0.67-1.22)$ \\
\hline \multicolumn{5}{|l|}{ Health } \\
\hline \multicolumn{5}{|l|}{ Number of medical conditions } \\
\hline None & $26(19)$ & $64(36)$ & 1 & 1 \\
\hline One & $42(30)$ & $60(34)$ & $1.51(1.06-2.17)^{* *}$ & $1.33(0.90-1.98)$ \\
\hline$\geq$ Two & $71(51)$ & $54(30)$ & $1.93(1.39-2.67)^{* *}$ & $1.87(1.30-2.67)^{* *}$ \\
\hline \multicolumn{5}{|l|}{ Hepatitis C status } \\
\hline Negative/Don't know & $55(40)$ & $58(33)$ & 1 & 1 \\
\hline Positive & $84(60)$ & $120(67)$ & $0.96(0.69-1.08)$ & $0.92(0.71-1.18)$ \\
\hline \multicolumn{5}{|l|}{ Ever attempted suicide } \\
\hline No & $54(39)$ & $110(62)$ & 1 & 1 \\
\hline Yes & $85(61)$ & $68(38)$ & $1.59(1.27-2.00)^{* *}$ & $1.36(1.03-1.78)^{*}$ \\
\hline \multicolumn{5}{|l|}{ Acquired brain injury } \\
\hline No & $109(78)$ & $148(83)$ & 1 & 1 \\
\hline Yes & $30(22)$ & $30(17)$ & $1.19(0.92-1.55)$ & $1.02(0.76-1.37)$ \\
\hline \multicolumn{5}{|l|}{ Criminological } \\
\hline Level of Service Inventory $(M, S D)$ & $5.64(1.32)$ & $5.31(1.46)$ & $1.08(1.00-1.16)$ & $1.08(0.96-1.21)$ \\
\hline \multicolumn{5}{|l|}{ Prison type } \\
\hline Maximum & $75(54)$ & $77(43)$ & 1 & 1 \\
\hline Medium & $38(27)$ & $53(30)$ & $0.86(0.66-1.11)$ & $0.95(0.72-1.26)$ \\
\hline Minimum & $26(19)$ & $48(27)$ & $0.71(0.53-.96)^{*}$ & $0.96(.66-1.41)$ \\
\hline \multicolumn{5}{|l|}{ Number of previous adult incarcerations } \\
\hline $0-3$ & $44(32)$ & $51(29)$ & 1 & 1 \\
\hline$\geq 4$ & $95(68)$ & $127(71)$ & $0.89(0.70-1.11)$ & $0.84(0.63-1.11)$ \\
\hline \multicolumn{5}{|l|}{ Youth detention ever } \\
\hline No & $72(52)$ & $63(35)$ & 1 & 1 \\
\hline Yes & $67(48)$ & $115(65)$ & $1.05(0.84-1.31)$ & $0.99(0.73-1.35)$ \\
\hline \multicolumn{5}{|l|}{ Alcohol and other drug use } \\
\hline \multicolumn{5}{|l|}{ Illicit substances used ${ }^{c}$} \\
\hline Heroin only & $22(16)$ & $41(23)$ & 1 & 1 \\
\hline Methamphetamine only & $46(33)$ & $74(42)$ & $1.54(1.08-2.19)^{*}$ & $1.52\left(1.05-2.22^{*}\right)$ \\
\hline Both heroin and methamphetamine & $71(51)$ & $63(35)$ & $1.07(0.72-1.58)$ & $0.96(0.63-1.48)$ \\
\hline
\end{tabular}


Table 1 Participant characteristics and modified poisson regression associations with poor psychiatric well-being among incarcerated men who reported regular injecting drug use prior to their current sentence $(n=317)$ (Continued)

\begin{tabular}{|c|c|c|c|c|}
\hline & $\begin{array}{l}\text { GHQ-12 } \\
(\geq 3) \\
(n=139)\end{array}$ & $\begin{array}{l}\text { GHQ-12 } \\
(\leq 2) \\
(n=178)\end{array}$ & $\mathrm{OR}^{\mathrm{a}}(95 \% \mathrm{Cl})$ & $\mathrm{aOR}^{\mathrm{b}}(95 \% \mathrm{Cl})$ \\
\hline \multicolumn{5}{|c|}{ High risk alcohol consumption $^{d}$} \\
\hline No & $98(71)$ & $133(75)$ & 1 & 1 \\
\hline Yes & $41(29)$ & $45(25)$ & $0.99(0.77-1.27)$ & $1.00(0.75-1.33)$ \\
\hline \multicolumn{5}{|c|}{ Age first injected } \\
\hline$\leq 16$ & $69(50)$ & $76(43)$ & 1 & 1 \\
\hline $17-20$ & $36(26)$ & $59(33)$ & $0.93(0.72-1.21)$ & $0.88(0.64-1.20)$ \\
\hline$\geq 21$ & $34(24)$ & $43(24)$ & $0.94(0.71-1.25)$ & $1.00(0.74-1.34)$ \\
\hline \multicolumn{5}{|c|}{ Poly-drug injecting drug use $\mathrm{e}^{\mathrm{e}}$} \\
\hline No & $47(34)$ & $63(35)$ & 1 & 1 \\
\hline Yes & $92(66)$ & $115(65)$ & $1.12(0.87-1.44)$ & $1.09(0.81-1.47)$ \\
\hline \multicolumn{5}{|c|}{ Adverse childhood experiences } \\
\hline \multicolumn{5}{|c|}{ Removed from home as a child ever } \\
\hline No & $94(68)$ & $137(77)$ & 1 & 1 \\
\hline Yes & $45(32)$ & $41(23)$ & $1.28(1.01-1.61)^{*}$ & $1.13(0.83-1.54)$ \\
\hline \multicolumn{5}{|c|}{ Expelled from school ever } \\
\hline No & $40(29)$ & $64(36)$ & 1 & 1 \\
\hline Yes & $99(71)$ & $114(64)$ & $1.21(0.94-1.57)$ & $1.05(0.76-1.46)$ \\
\hline
\end{tabular}

Note: $P$ values: ${ }^{*}=p<.05 ;{ }^{*}=p<.001 ;{ }^{\mathrm{a}} \mathrm{OR}=$ Odds ratio; ${ }^{\mathrm{b}}$ aOR $=$ Adjusted odds ratio; ${ }^{\mathrm{c}}$ At least one use, by any route of administration, in the week before their current sentence; ${ }^{\mathrm{d}}$ The 12 months before their current sentence; ${ }^{\mathrm{e}}$ The week before their current sentence

\section{Associations with current poor psychiatric well-being}

In bivariate analyses, history of suicide attempt, number of self-reported medical conditions, use of crystal methamphetamine (by any route of administration) in the week prior to their current sentence, and being removed from the home as a child were statistically significantly associated with current poor psychiatric well-being. Compared to participants released from a maximum security prison, participants recruited from the minimum security prison were less likely to have current poor psychiatric well-being.

In the multivariate model, history of suicide attempt $(\mathrm{aOR}=1.36$, 95\% CI 1.03-1.78), reporting two or more medical conditions $(\mathrm{aOR}=1.87,95 \% \mathrm{CI} 1.30-2.67)$ and use of crystal methamphetamine in the week prior to their current sentence $(\mathrm{aOR}=1.52,95 \% \mathrm{CI} 1.05-2.22)$ remained statistically significantly associated with current poor psychiatric well-being (Table 1). Post-model testing was conducted to determine overall fit. All variables in the multivariable model showed $\mathrm{VIF}<2$, suggesting no collinearity.

\section{Discussion}

In a sample of incarcerated men who reported regular injecting drug use prior to their current sentence, $44 \%$ were classified as experiencing current current poor psychiatric well-being as measured by the GHQ-12, indicating potential unmet need during periods of incarceration for people detained in prison regarding mental health service delivery. We found that history of suicide attempt, having two or more self-reported medical conditions, and use of crystal methamphetamine in the week prior to their current sentence were independently associated with an increased likelihood of current poor psychiatric well-being.

Findings from several studies indiate that suicide rates among people in prison and those released from prison are higher than among the general community (Artenie et al., 2015; Haglund et al., 2014; Meltzer et al., 2003; Spittal et al., 2014). In addition to standard history and examination by medical professionals, our findings support the inclusion of screening for past suicidial behaviours during reception in-take procedures. Referrals of individuals meeting criteria of past suicidal behaviours with histories of injecting drug use during this time could provide opportunities for additional assessment by advancedtrainedmental health professionals with specialist clinical expertise (Brunette et al., 2008), particularly pertaining to dual diagnosis. In correctional facilities in England and Wales analogous systems have been implemented (Hopkin et al., 2017). Local adaptions to screening processes in-prison have shown to statistically significantly improve measures of depression, anxiety and psychological distress for people detained in prison at high-risk of psychosis (Evans et al., 2017) and be relatively inexpensive (Brown, Cullen, Kooyman, \& Forrester, 2015). 
Two or more physical health conditions remained associated with current poor psychiatric well-being. Chronic pain and disease are well known to impact on psychiatric well-being (Burke et al., 2015), particularly for those with severe mental illness (Miller et al., 2006). Our findings highlight the need for coordination of treatment services in correctional and community settings, where the prevalence and co-occurrence of both conditions is high. The integration of physical health assessment, physical activity programs (Richardson et al., 2005), and targeted healthy well-being education (Smith et al., 2007) into community based psychiatric care services have shown to be successful models for increasing coordination of service delivery by health professionals and reducing the health burden for individuals. The introduction of similar health service delivery models in prison for people with dual diagnosis may foster the transition to community and encourage the continuation of care once released. In Victorian correctional settings, treatment programs for mental health conditions and substance dependence are delivered separately. The forthcoming results of a randomised trial (Van Dorn et al., 2017) combining two evidence-based treatments (i.e., motivational interviewing and integrated group therapy) for substance dependence and mental health disorders aimed at increasing treatment engagement from prison to community is likely to provide insight into the feasibility of such a model for people with dual diagnosis detained in prison.

Participants who reported using crystal methamphetamine only (by any route of administration) in the week prior to their current sentence were more likely to have current poor psychiatric well-being than men who had used heroin only or crystal methamphetamine and heroin. The use of crystal methamphetamine has been shown to be associated with many physical and psychiatric problems, particularly psychosis (Degenhardt, \& Topp, 2003; Degenhardt et al., 2008; Marshall, \& Werb, 2010). In addition, for those with pre-existing mental health disorders, the impact of dependent substance use may be greater (Drake, 2007). Prison program and health services often focus resources towards people detained in prison with a complex array of health and psychosocial issues that may predispose them to recurring morbidity and reoffending. Our findings suggest that prioritising people detained in prison for mental health screening and follow-up services on the basis of types of drugs used or the types of drugs related to their offending behaviours may provide opportunities to appropriate target health service referrals in prison and in pre-release planning. This prioritisation is particularly pertinent in the context of contemporary changes in the drug use and harms among PWID. Methamphetamine has now overtaken heroin as the most commonly injected drug in Australia (Stafford, \& Breen, 2017), substantial increases in the purity of methamphetamine have been detected (Scott et al., 2015) and increases have been observed in methamphetamine-related arrests and presentations of amphetamine use disorders and amphetamine psychosis at mental health services in some Australian jurisdictions (Degenhardt et al., 2017). In this context it may be beneficial to consider the development of dual service models of care that address both mental health and methamphetamine dependence simultaneously rather than have mental health and addiction specialists working with people detained in prison in relative isolation (Cumming et al., 2016). Just models may become more feasible in the future with promising methamphetaminereplacement pharmacotherapies being trialled (McKetin et al., 2017). Our findings should be considered in relation to study limitations. Self-report survey methodologies are prone to recall and social desirability biases. However, these methods among PWID have previously shown reliability relating to the collection of sensitive information (Darke, 1998; Ross et al., 1995), and have provided predictable results (Cutcher et al., 2014). The GHQ-12 has shown some variability across population groups in detecting current psychiatric symptoms (Goldberg et al., 1998; Willmott et al., 2004). However, is used widely as a screening tool for mental health referral (Hewitt et al., 2011). The findings from this study should therefore be seen in the context of identifying potential unmet need and for informing care and referral pathways, rather than the definitive identification and diagnosis of psychiatric morbidity. The authors have presented baseline (i.e, crosssectional) data from this larger prospective cohort meaning we were unable to make causal inferences. Extensive future prospective and retrospective data linakge to health, criminogenic and social service data in this study will provide opportunities to investigate the temporal relationships between a range of exposures and mental health disorders among participants. This will also provide an opportunity to examine relationships of dual diagnosis with ongoing health, crime and reoffending risk to inform general and targeted service need.

\section{Conclusion}

We observed a high prevalence of current poor psychiatric well-being and potential service need in a sample of incarcerated men who injected drugs regularly prior to their current sentence. Comprehensively addressing the healthrelated needs for this vulnerable population will require a multidisciplinary approach. Enhancing opportunities to screen and triage people detained in prison for mental health and other potential co-occurring health issues at appropriate points in their engagement with the criminal justice system will provide opportunities to better address their individual health needs and reoffending risk. 


\section{Acknowledgements}

All the participants involved in the Prison and Transition Health Study for their time and knowledge and the Burnet Institute fieldwork team for their tireless efforts with study follow-up.

\section{Funding}

The research was funded by a National Health and Medical Research Council Grant (APP1029915). RC is supported by the Australian Government Research Training Program Scholarship. MS is supported by NHMRC Career Development Fellowship APP1090445. SK is supported by NHMRC Senior Research Fellowship APP1078168.

\section{Availability of data and materials}

There is potential for data availability with ethics approval from each ethics body.

\section{Authors' contributions}

$\mathrm{RC}$ led the concept of the paper, including writing, editing, statistical analysis, and author coordination. MC provided assistance with statistical analysis including data cleaning. AK, CA, and PD provided editorial feedback. SK provided editorial feedback and guidance for paper development. MS and $\mathrm{JO}$ are primary supervisors for RC's Doctor of Psychology and thus provided guidance, editorial support throughout the duration of planning and writing. All authors read and approved the final manuscript.

\section{Ethics approval and consent to participate}

The study was approved by the Alfred Hospital Human Research Ethics Committee (79/12) and the Victorian Department of Justice Human Research Ethics Committee (CF/14/10169). Participants were required to provide informed, written consent prior to study inclusion.

\section{Consent for publication}

The authors' consent to publication.

\section{Competing interests}

The authors declare that they have no competing interests.

\section{Publisher's Note}

Springer Nature remains neutral with regard to jurisdictional claims in published maps and institutional affiliations.

\section{Author details}

${ }^{1}$ Centre for Forensic Behavioural Science, Swinburne University of Technology \& Forensicare, Melbourne, Australia. ${ }^{2}$ Behaviours and Health Risks, Burnet Institute, Melbourne, Australia. ${ }^{3}$ School of Public Health and Preventive Medicine, Monash University, Melbourne, Australia. ${ }^{4}$ Centre for Adolescent Health, Murdoch Children's Research Institute, Melbourne, Australia. ${ }^{5}$ Centre for Mental Health, Melbourne School of Population and Global Health, University of Melbourne, Melbourne, Australia. ${ }^{6}$ Griffith Criminology Institute, Griffith University, Brisbane, Australia. ${ }^{7}$ Mater Research Institute-UQ, University of Queensland, Mount Gravatt, Australia.

Received: 30 August 2017 Accepted: 2 January 2018

Published online: 13 January 2018

\section{References}

Andrews, DA, \& Bonta, J (1998). The level of service inventory-revised:Screening version. Toronto, Canada: Multi-Health Systems.

Artenie, AA, Bruneau, J, Zang, G, Lespérance, F, Renaud, J, Tremblay, J, \& JutrasAswad, D. (2015). Associations of substance use patterns with attempted suicide among persons who inject drugs: Can distinct use patterns play a role? Drug and Alcohol Dependence, 147, 208-214. https://doi.org/10.1016/j. drugalcdep.2014.11.011.

Australian Bureau of Statistics. (2016). Prisoners in Australia, 2016. Retrieved from http://www.abs.gov.au/Crime-and-Justice.

Australian Institute of Health and Welfare. (2015). The Health of Australia's Prisoners 2015. Retrieved from https://www.aihw.gov.au/reports-statistics/populationgroups/prisoners/overview.

Brink, JH, Doherty, D, \& Boer, A. (2001). Mental disorder in federal offenders: A Canadian prevalence study. International Journal of Law and Psychiatry, 24(45), 339-356. https://doi.org/10.1016/S0160-2527(01)00071-1.
Brown, K., Cullen, A., Kooyman, I., \& Forrester, A. (2015). Mental health expertise at prison reception. The Journal of Forensic Psychiatry and Psychology, 26(1), 107-115. https://doi.org/10.1080/14789949.2014.955810.

Brunette, MF, Asher, D, Whitley, R, Lutz, WJ, Wieder, BL, Jones, AM, \& McHugo, GJ. (2008). Implementation of integrated dual disorders treatment: A qualitative analysis of facilitators and barriers. Psychiatric Services, 59(9), 989-995. https:// doi.org/10.1176/ps.2008.59.9.989.

Burke, ALJ, Mathias, JL, \& Denson, LA. (2015). Psychological functioning of people living with chronic pain: A meta-analytic review. British Journal of Clinical Psychology, 54(3), 345-360. https://doi.org/10.1111/bjc.12078.

Butler, T, Indig, D, Allnutt, S, \& Mamoon, H. (2011). Co-occurring mental illness and substance use disorder among Australian prisoners. Drug and Alcohol Review,30(2),188-194. https://doi.org/10.1111/j.1465-3362.2010. 00216.x.

Butzin, CA, Martin, SS, \& Inciardi, JA. (2005). Treatment during transition from prison to community and subsequent illicit drug use. Journal of Substance Abuse Treatment, 28(4), 351-358. https://doi.org/10.1016/j.jsat. 2005.02.009

Chang, Z, Lichtenstein, P, Larsson, H, \& Fazel, S. (2015). Substance use disorders, psychiatric disorders, and mortality after release from prison: A nationwide longitudinal cohort study. Lancet Psychiatry, 2(5), 422-430. https://doi.org/10. 1016/s2215-0366(15)00088-7.

Cumming, C, Troeung, L, Young, JT, Kelty, E, \& Preen, DB. (2016). Barriers to accessing methamphetamine treatment: A systematic review and metaanalysis. Drug and Alcohol Dependence, 168, 263-273. https://doi.org/10.1016/ j.drugalcdep.2016.10.001.

Cutcher, Z, Degenhardt, L, Alati, R, \& Kinner, SA. (2014). Poor health and social outcomes for ex-prisoners with a history of mental disorder: A longitudinal study. Australian and New Zealand Journal of Public Health, 38(5), 424-429. https://doi.org/10.1111/1753-6405.12207.

Darke, S. (1998). Self-report among injecting drug users: A review. Drug and Alcohol Dependence, 51(3), 253-263. https://doi.org/10.1016/S03768716(98)00028-3

Davis, MR, Ogloff, JRP, Rivers, G, \& Ross, S. (2007). The Identification of Mental Disorders in the Criminal Justice System (1921185368). Retrieved from http:// crg.aic.gov.au/reports/2006-ogloff.pdf.

Degenhardt, L, Roxburgh, A, Black, E, Bruno, R, Campbell, G, Kinner, SA, \& Fetherston, J. (2008). The epidemiology of methamphetamine use and harm in Australia. Drug and Alcohol Review, 27(3), 243-252. https://doi.org/10.1080/ 09595230801950572

Degenhardt, L, Sara, G, McKetin, R, Roxburgh, A, Dobbins, T, Farrell, M, Burns, L, \& Hall, WD. (2017). Crystalline methamphetamine use and methamphetaminerelated harms in Australia. Drug and Alcohol Review, 36(2), 160-170. https:// doi.org/10.1111/dar.12426

Degenhardt, L, \& Topp, L. (2003). 'Crystal meth' use among polydrug users in Sydney's dance party subculture: Characteristics, use patterns and associated harms. International Journal of Drug Policy, 14(1), 17-24. https://doi.org/10. 1016/S0955-3959(02)00200-1.

Dias, S, Ware, RS, Kinner, SA, \& Lennox, NG. (2013). Co-occurring mental disorder and intellectual disability in a large sample of Australian prisoners. Australian \& New Zealand Journal of Psychiatry, 47(10), 938-944. https://doi.org/10.1177/ 0004867413492220

Drake, RE. (2007). Dual diagnosis. Psychiatry, 6(9), 381-384. https://doi.org/10. 1016/j.mppsy.2007.07.001.

Drake, RE, \& Wallach, MA. (2000). Dual diagnosis: 15 years of progress. Psychiatric Services, 51(9), 1126-1129. https://doi.org/10.1176/appi.ps.51.9.1126.

Durand, E, Chevignard, M, Ruet, A, Dereix, A, Jourdan, C, \& Pradat-Diehl, P. (2017). History of traumatic brain injury in prison populations: A systematic review. Annals of Physical and Rehabilitation Medicine, 60(2), 95-101. https://doi.org/ 10.1016/j.rehab.2017.02.003

Evans, C, Forrester, A, Jarrett, M, Huddy, V, Campbell, CA, Byrne, M, Craig, T, \& Valmaggia, L. (2017). Early detection and early intervention in prison: Improving outcomes and reducing prison returns. The Journal of Forensic Psychiatry \& Psychology, 28(1), 91-107. https://doi.org/10.1080/14789949.2016. 1261174.

Every-Palmer, S, Brink, J, Chern, TP, Choi, W-K, Hern-Yee, JG, Green, B, Heffernan, E, Johnson, SB, Kachaeva, M, Shiina, A, Walker, D, Wu, K, Wang, X, \& Mellsop, G. (2014). Review of psychiatric services to mentally disordered offenders around the Pacific Rim. Asia-Pacific Psychiatry, 6(1), 1-17. https://doi.org/10.1111/appy.12109.

Fazel, S, \& Baillargeon, J. (2010). The health of prisoners. The Lancet, 377(9769), 956-965. https://doi.org/10.1016/S0140-6736(10)61053-7. 
Fazel, S, \& Danesh, J. (2002). Serious mental disorder in 23000 prisoners: A systematic review of 62 surveys. The Lancet, 359(9306), 545-550. https://doi. org/10.1016/S0140-6736(02)07740-1.

Ferguson, AM, Ogloff, JRP, \& Thomson, L. (2009). Predicting recidivism by mentally disordered offenders using the LSI-R:SV. Criminal Justice and Behavior, 36(1), 5-20. https://doi.org/10.1177/0093854808326525.

Goldberg, D (1992). General health questionnaire (GHQ-12). Windsor, UK: Nfer-Nelson.

Goldberg, D, Gater, R, Sartorius, N, Ustun, TB, Piccinelli, M, Gureje, O, \& Rutter, C. (1997). The validity of two versions of the GHQ in the WHO study of mental illness in general health care. Psychological Medicine, 27(01), 191-197.

Goldberg, D, Oldehinkel, T, \& Ormel, J. (1998). Why GHQ threshold varies from one place to another. Psychological Medicine, 28(04), 915-921.

Haglund, A, Tidemalm, D, Jokinen, J, Långström, N, Lichtenstein, P, Fazel, S, \& Runeson, B. (2014). Suicide after release from prison: A population-based cohort study from Sweden. Journal of Clinical Psychiatry, 75(10), 1047-1053. https://doi.org/10.4088/JCP.13m08967.

Hewitt, CE, Perry, AE, Adams, B, \& Gilbody, SM. (2011). Screening and case finding for depression in offender populations: A systematic review of diagnostic properties. Journal of Affective Disorders, 128(1), 72-82. https://doi.org/10. 1016/j.jad.2010.06.029

Hopkin, G, Samele, C, Singh, K, Craig, T, Valmaggia, L, \& Forrester, A. (2017). Prison mental health in-reach: The effect of open referral pathways. Psychiatry, Psychology and Law, 24(1), 152-158. https://doi.org/10.1080/13218719.2016.1197813.

Horsfall, J, Cleary, M, Hunt, GE, \& Walter, G. (2009). Psychosocial treatments for people with co-occurring severe mental illnesses and substance use disorders (dual diagnosis): A review of empirical evidence. Harvard Review of Psychiatry, 17(1), 24-34. https://doi.org/10.1080/10673220902724599.

Kinner, SA. (2006). Continuity of health impairment and substance misuse among adult prisoners in Queensland, Australia. International Journal of Prisoner Health, 2(2), 101-113. https://doi.org/10.1080/17449200600935711.

Markowitz, FE. (2011). Mental illness, crime, and violence: Risk, context, and social control. Aggression and Violent Behavior, 16(1), 36-44. https://doi.org/10.1016/ j.avb.2010.10.003.

Marshall, BDL, \& Werb, D. (2010). Health outcomes associated with methamphetamine use among young people: A systematic review. Addiction, 105(6). https://doi.org/10.1111/j.1360-0443.2010.02932.x.

McCausland, R, Johnson, S, Baldry, E, \& Cohen, A. (2013). People with mental health disorders and cognitive impairment in the criminal justice system: Cost-benefit analysis of early support and diversion. Retrieved from https:// www.humanrights.gov.au/sites/default/files/document/publication/ Cost\%20benefit\%20analysis.pdf.

McKetin, R, Dean, OM, Baker, AL, Carter, G, Turner, A, Kelly, PJ, \& Berk, M. (2017). A potential role for $\mathrm{N}$-acetylcysteine in the management of methamphetamine dependence. Drug and Alcohol Review, 36(2), 153-159. https://doi.org/10. $1111 /$ dar.12414

Meltzer, H, Jenkins, R, Singleton, N, Charlton, J, \& Yar, M. (2003). Non-fatal suicidal behaviour among prisoners. International Review of Psychiatry, 15(1-2), 148149. https://doi.org/10.1080/0954026021000046083.

Mental Health Act 2014 (Vic). Retrieved from http://www7.austlii.edu.au/cgi-bin/ viewdb/au/legis/vic/num_act/mha20142602014174/.

Miller, BJ, Paschall, CB, \& Svendsen, DP. (2006). Mortality and medical comorbidity among patients with serious mental illness. Psychiatric Services, 57(10), 1482-1487.

Munetz, MR, Grande, TP, \& Chambers, MR. (2001). The incarceration of individuals with severe mental disorders. Community Mental Health Journal, 37(4), 361372. https://doi.org/10.1023/a:1017508826264

O'Rourke, C, Linden, MA, Lohan, M, \& Bates-Gaston, J. (2016). Traumatic brain injury and co-occurring problems in prison populations: A systematic review. Brain Injury, 30(7), 839-854. https://doi.org/10.3109/02699052.2016.1146967.

Ogloff, JRP, Lemphers, A, \& Dwyer, C. (2004). Dual diagnosis in an Australian forensic psychiatric hospital: Prevalence and implications for services. Behavioral Sciences \& the Law, 22(4), 543-562. https://doi.org/10.1002/bsl.604.

Ogloff, JRP, Pfeifer, JE, Shepherd, SM, \& Ciorciari, J. (2017). Assessing the mental health, substance abuse, cognitive functioning, and social/emotional wellbeing needs of aboriginal prisoners in Australia. Journal of Correctional Health Care, 23(4), 398-411. https://doi.org/10.1177/1078345817723345.

Ogloff, JRP, Talevski, D, Lemphers, A, Wood, M, \& Simmons, M. (2015). Cooccurring mental illness, substance use disorders, and antisocial personality disorder among clients of forensic mental health services. Psychiatric Rehabilitation Journal, 38(1), 16-23. https://doi.org/10.1037/prj0000088.

Reekie, J. M., Levy, M. H., Richards, A. H., Wake, C. J., Siddall, D. A., Beasley, H. Kumar, S., \& Butler, T. (2014). Trends in prevalence of HIV infection, hepatitis B and hepatitis C among Australian prisoners-2004, 2007, 2010. Medical Journal of Australia, 200(5), 277-280. https://doi.org/10.5694/mja13.11062

Richardson, CR, Faulkner, G, McDevitt, J, Skrinar, GS, Hutchinson, DS, \& Piette, JD. (2005). Integrating physical activity into mental health services for persons with serious mental illness. Psychiatric Services, 56(3), 324-331. https://doi.org/ 10.1176/appi.ps.56.3.324.

Ross, MW, Stowe, A, Wodak, A, \& Gold, J. (1995). Reliability of interview responses of injecting drug users. Journal of Addictive Diseases, 14(2), 1-12. https://doi. org/10.1300/J069v14n02_01.

Schilders, MR, \& Ogloff, JRP. (2016). Stability of life-time psychiatric diagnoses among offenders in community and prison settings. Journal of Forensic Psychiatry \& Psychology, 28(1), 133-154. https://doi.org/10.1080/14789949.2016.1263676.

Scott, N, Carrotte, ER, Higgs, P, Stoove, MA, Aitken, CK, \& Dietze, P. (2017). Longitudinal changes in personal wellbeing in a cohort of people who inject drugs. PLoS One, 12, e0178474. https://doi.org/10.1371/journal.pone.0178474.

Scott, N, Caulkins, JP, Ritter, A, Quinn, C, \& Dietze, P. (2015). High-frequency drug purity and price series as tools for explaining drug trends and harms in Victoria, Australia. Addiction, 110(1), 120-128. https://doi.org/10.1111/add.12740.

Senior, J, Birmingham, L, Harty, MA, Hassan, L, Hayes, AJ, Kendall, K, King, C, Lathlean, J, Lowthian, C, Mills, A, Webb, R, Thornicroft, G, Shaw, J. (2013). Identification and management of prisoners with severe psychiatric illness by specialist mental health services. Psychological Medicine, 43(7), 1511-1520. https://doi.org/10.1017/S0033291712002073.

Sirdifield, C, Gojkovic, D, Brooker, C, \& Ferriter, M. (2009). A systematic review of research on the epidemiology of mental health disorders in prison populations: A summary of findings. The Journal of Forensic Psychiatry \& Psychology, 20(sup1), S78-S101. https://doi.org/10.1080/14789940802594445.

Smith, S, Yeomans, D, Bushe, CJP, Eriksson, C, Harrison, T, Holmes, R, MynorsWallis, L, Oatway, H, \& Sullivan, G. (2007). A well-being programme in severe mental illness. Reducing risk for physical ill-health: A post-programme service evaluation at 2 years. European Psychiatry, 22(7), 413-418. https://doi.org/10. 1016/j.eurpsy.2007.07.002

Snow, KJ, Young, JT, Preen, DB, Lennox, NG, \& Kinner, SA. (2014). Incidence and correlates of hepatitis $C$ virus infection in a large cohort of prisoners who have injected drugs. BMC Public Health, 14, 830. https://doi.org/10.1186/14712458-14-830

Spittal, MJ, Forsyth, S, Pirkis, J, Alati, R, \& Kinner, SA. (2014). Suicide in adults released from prison in Queensland, Australia: A cohort study. Journal of Epidemiology and Community Health, 68(10), 993-998. https://doi.org/10. 1136/jech-2014-204295.

Stafford, J, \& Breen, C (2017). Australian drug trends 2016. Findings from the illicit drug reporting system (IDRS). Australian drug trend series. No. 163. Sydney, Australia: National Drug and Alcohol Research Centre, UNSW Australia.

StataCorp (2015). Stata statistical software: Release 14. College Station, TX: StataCorp LP.

Van Dorn, RA, Desmarais, SL, Rade, CB, Burris, EN, Cuddeback, GS, Johnson, KL, Tueller, SJ, Comfort, ML, \& Mueser, KT. (2017). Jail-to-community treatment continuum for adults with co-occurring substance use and mental disorders: Study protocol for a pilot randomized controlled trial. BMC Trials, 365(18). https://doi.org/10.1186/s13063-017-2088-z.

Vescio, MF, Longo, B, Babudieri, S, Starnini, G, Carbonara, S, Rezza, G, \& Monarca, R. (2008). Correlates of hepatitis $C$ virus seropositivity in prison inmates: A meta-analysis. Journal of Epidemiology and Community Health, 62(4), 305-313. https://doi.org/10.1136/jech.2006.051599.

Warden, D., Sanchez, K., Greer, T., Carmody, T., Walker, R., dela Cruz, A., Marisa Toups. M., Rethorst, C., \& Trivedi, M. H. (2016). Demographic and clinical characteristics of current comorbid psychiatric disorders in a randomized clinical trial for adults with stimulant use disorders. Psychiatry Research, 246, 136-141. https://doi.org/10.1016/.jpsychres.2016.09.007.

Willmott, SA, Boardman, JAP, Henshaw, CA, \& Jones, PW. (2004). Understanding general health questionnaire $(\mathrm{GHQ}-28)$ score and its threshold. Social Psychiatry and Psychiatric Epidemiology, 39(8), 613-617. https://doi.org/10. 1007/s00127-004-0801-1.

Winter, RJ, Stoove, M, Degenhardt, L, Hellard, ME, Spelman, T, Jenkinson, R, \& Kinner, SA. (2015). Incidence and predictors of non-fatal drug overdose after release from prison among people who inject drugs in Queensland, Australia. Drug and Alcohol Dependence, 153, 43-49. https://doi.org/10.1016/j. drugalcdep.2015.06.011.

Youssef, IM, Fahmy, MT, Haggag, WL, Mohamed, KA, \& Baalash, AA. (2016). Dual diagnosis and suicide probability in poly-drug users. Journal of the College of Physicians and Surgeons Pakistan, 26(2), 130-133. 